\title{
PULSE LOSS AND VOLTAGE MEASUREMENTS ON SUPERCONDUCTING MAGNETS *
}

S. S. Shen and H. T. Yeh

Oak Ridge National Laboratory

Oak Ridge, Tennessee $\mathbf{3 7 8 3 0}$

$$
\text { CONF }-760829--10
$$

\author{
For Presentation \\ Applied Superconductivity Conference \\ Stanford, California \\ August $17-20,1976$
}

By acceptance of this article, the publisher or recipient acknowledges the U.S. Government's right to retain a non - exclusivc, royaity - frce licen:e in and to any copyright covering the article.

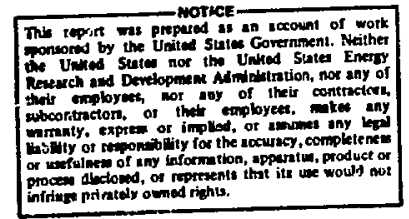

${ }^{*}$ Research sponsored by the Energy Research and Development Administration under contract with Union Carbide Corporation.

CONTRAT NO. W-7405-ENG-26 


\section{ABSTRACT}

Thls paper describes an electrical method for measuring pulse losses and compensated voltage in superconducting magnets. Test results from two pulsed solenoids are recorded and analyzed digitally by computer. Dependance of loss performance on $B_{\text {max }}$ and $B$ is studied. The effects of conductor motion and presence of normal metal on the loss performance are also discussed.

\section{INTRODUCTION}

The pololdal systems of the Experimental Power Reactor (EPR) require fast flux swing $(\sim 7 \mathrm{~T} / \mathrm{sec})$ at high field $(\sim 7 \mathrm{~T})$ during part of the operation cycle. A diagnostic tool is needed for testing the pulsed magnets of the systems and understanding the assoc1ated loss phenomena. Such a tool has been developed by Wilson 1 based on the silape and area of the hysteresis loss loop. However, additional information about the loss mechanisms could be obtained if the loss voltage waveform due to flux change inside the conductor is monitored and callbrated.

Our method is based or analysis of the voltage waveform. The method of callbration is discussed in detail below. Bestdes providing insights into the $108 s$ mechanisms, the calibrated loss voltage is belleved to be the most sensitive signal for detecting any instability, such as flux fump or mechanical motion, and can be used for reliable quench detection and coll protection.

This paper presents experimental results of pulse $108 s$ measurements for two solenoids operated under conditions similar to those in EPR. Main parameters of the solenolds are given in Table $I$.

TABLE I

Main Farameters of Two Puised Solenoids ${ }^{a}$

\begin{tabular}{lll}
\hline & \multicolumn{1}{c}{ Yagnet I } & Magnet II \\
\hline Bore, cm & 5.1 & 5.1 \\
Length, cm & 23.4 & 15.5 \\
Inductance, H & 0.096 & 0.131 \\
Maximum Fleld, T & 7.2 & 5.2 \\
Stored Energy, k.J & 31 & 12 \\
Conductor & 27 strand, braided & 35 strand, braided \\
& Cu matrix & Cu matrix \\
Winding Scheme & Potted & Tightly wound \\
\hline
\end{tabular}

${ }^{a}$ Designed by M. S. Lubeil and fabricated by W. J. Schill at ORNL.

\section{MEASUREMENT SCHEME}

A schematic diagram of our measurement system is shown in Fig. 1. The $\Delta V$ in Fig. I represents the com-

Manuscript received August 17, 1976.

* Research sponsored by the Energy Research and Development Administration under contract with Union Carbide Corporation.

${ }^{\dagger}$ Superconducting Magnet Development Program, Thermoniclear Division, ORNL, Oak Ridge, Tennessee 378?n, penssiced 10sis. voltagt due to the flux change, $d \phi_{0} / d t$, inside the superconductor. All flux change outside, $\mathrm{d} \phi_{\text {ext }} / \mathrm{dt}$, is compensated by using Rogowski coll. The criteria for obtaining a perfect compensation are given in Section III.

Loss can be calculated with either of the following two equations:

$$
\begin{aligned}
& Q=\frac{1}{K_{0}} \int \Delta V I d t \text { (J/cycle), } \\
& Q=\frac{1}{K_{0}} \int \delta \Delta V d t d I \text { (J/cycle). }
\end{aligned}
$$

The $\phi-I$ curve of the magnet can be obtained from Eq. (2). Each of our test cycles consists of changing the current from zero to maximum and back to zero again. It should be noted that the cycling history will strongly affect both the value of $q$ and the shape of the $\phi-I$ curve.

\section{ARALYSIS}

General

It has been proved ${ }^{1}$ that the integral of the compensated voltage signal is equal to

$$
\int_{0}^{t} \Delta v\left(t^{\prime}\right) d t^{\prime} d I==\sum_{1} \int \mu_{0} M_{1} \mathrm{dH}_{1} \text { f } \Delta v_{1}
$$

since $\phi_{0}(t)=\int_{0}^{t} \Delta v\left(t^{\prime}\right) d t^{\prime}$, from Eq. (3)

$$
\phi_{0}(t)=\sum_{1} \mu_{0} M_{i} h_{1} f \Delta v_{i},
$$

where $h_{i}=H_{1} / I$.

\section{Shielding Region}

For very small transport current, superconductor regions behave like a perfect diamagnet. Hence

$$
\mathbf{M}_{\mathbf{i}}=-2 \mathbf{H}_{\mathbf{i}},
$$

where the factor of 2 is due to the demagnetization effect of a filamentary conductor in the presence of perpendicular magnetic fleld. Therefore,

$$
\phi_{0}(t)=-\frac{2 I f}{\mu_{0}} \sum_{1} b_{1}^{2} \Delta v_{1},
$$

where $b_{1}=\mu_{0} h_{1}$. Since all the quantities on the right side are known, Eq. (5) can be used to calibrate the compensation. This equation should hold regardless of the $B$ used, provided that the coupling loss is still negligible. Figure 2 shows a typical $\phi_{0}-I$ curve where Eq. (5) represents the initial 11near region.

\section{Remanant Flux}

Flur is trapped at the end of each test cycle. As shown in section IV, differenc test cycles end in the same amount of trapped flux, provided their maximum currents all exceed a certain threshold. Let $A_{r}$ denote the corresponding remanent magnetization. Eq. (4) gives for $I=0$ at the end of the cycle

$$
\phi_{0}(I=0)=\mu_{0} M_{r} \Gamma \sum h_{1} \Delta v_{1} .
$$

This equation could be used to predict the value of $\mathbf{M}_{\mathbf{T}}$. 
Differentiating Eq. (4). the $108 s$ voltage can be expressed as

$$
\Delta V(t)=\sum_{1} \mu_{0} \in \frac{d H_{1}}{d H_{1}} \frac{d H_{1}}{d t} h_{1} \Delta v_{1},
$$

If the family of short sample $M-H$ curves is available, voltage can be predicted by $\mathrm{Eq}$. (7). A typical compensated voltage waveform is shown. In F1g. 2 .

\section{Hormal Metal Loss and Conductor Mot ion}

The loss voltage signal should reflect any normal metal circult present through their mutual inductive coupling to the magnet. Therefore, eddy loss in the normal metal can be measured. Experimental results of loss with the presence of copper rod are given in Section IV.

Conductor motion w1ll offset the compensation and hence will result in abnormality of the loss vitage waveform and the $\phi-I$ curve. This phenomenon is slearly observed In the unpotted magnet (Magnet II).

\section{RESULTS AND DISCUSSION}

\section{Magnet I}

Hysteresis Losses. Fr $L$ l low cycling ( $<0.1 \mathrm{~T} / \mathrm{sec}$ ) transport current, the measured hysteresis losses per cycle are given in Fig. 3. Similar to short sample results, it clearly shows two different transport current-dependence regions. In the $I^{3}$ region, most filaments are not yet saturated by the external fleld, whereas the I linear region represents completely penetrated flux-flow region. Figure 4 shows a sequence of $\phi-I$ curves for monotonlcally decreasing peak value of ramp current. Figure 5 shows the same series for smaller currents ( $\leq 200 \mathrm{~A})$.

Normal Metal Effect. In order to demonstrate normal metal coupling effect, a 13-cm-long cylinder of $\mathrm{Cu}$ with a volume of $1.45 \times 10^{-4} \mathrm{~m}^{3}(\approx 50 \%$ of Cu matrix in the magnet winding) is placed Inside the magnet bore. As the magnet is cycled, eddy current lusses Induced in the Cu cylinder are measured together with the loss in winding. Figure 6 shows the results. The peak value of the ramp current $18400 \mathrm{~A}$ corresponding to $4 \mathrm{~T}$ at center of the magnet. The fastest ramp speed shown in the figure is about $0.6 \mathrm{~T} / \mathrm{sec}$. Figure 7 shows a comparison between two ramp cycles with and without normal metal coupling circuit. The difference of the areas is due to the eddy current losses in $\mathrm{Cu}$.

Discharging Test. Discharging test results are presented In Fig. 8. Measured losses for slowly charging up, then quickly dumping are plotted vs discharge time constant. The results have shown that the magnet can be discharged from $6.2 \mathrm{~T}$ at a rate of $10 \mathrm{~T} / \mathrm{sec}$ without going normal. This may be a viable scheme for operating ohmic heating colls in a tokamak fusion reactor. 2

\section{Magnet II}

Hysteres1s Loss. Measured hystert-is losses per cycle for this tightiy wound magnet are presented in Fig. 9. The $I^{3}$ dependence region is clearly shown. For current higher than $150 \mathrm{~A}$ ( $2 \mathrm{~T}$ at conductor), conductor motion was detected. Figure 10 gives corresponding voltage waveform and $\phi-I$ curve. Note that the voltage Increase during the charging pericd implies that conductor motion offsets the compensation and thus causes distortion in $\phi-I$ curve shape.
It has been shown that the electric method of 108 weasurement can yleld not only the total energy Loss but also the compensated voltage waveform. Methods of its compensation and its application as a diagnostic tool for magnets are demonstrated. Theoretical formulas for voltage waveform in terms of the short sample characteristics are also given. Quench detection and protection schemes for nuiti-coll maget cystems In a tokamak fusion reactor have been designed based on this method of loss voltage measurement. ${ }^{3}$

\section{ACKNOWLEGKENTS}

The authors wish to thank $H . S$. Lube: 1 and $H . A$. Fietz for their constant encouragement and helpful comments. Technical assistance from C. H. Fitzpatrisk is greatly appreclaced. We are also grateful for the collaboration and discussions with all members of Superconductivity Magnet Development project of OiNL. In particular, special thanks to R. E. Schwall, fo: his many helpful suggestions and assistance.

\section{REFERENCES}

1. K. N. Wtlson, "An Improved Technique for Measuring Hysteresis Loss in Supercnnducting Magnets", Cryogenics: 361 (1973).

2. J. K. Bajlou, R. E. Schwall, S. S. Shen, H. T. Yeh, private comunication.

3. H. T. Yeh and J. H. Lue, "The Interaction and Protection of Superconducting Poloidal Field Coils and Toroidai Field Colls in a Tekamak Experimental Power Reactor", paper presented at the 1976 IEEE International Conference on Plasma Sclence, Austin, Texas, May 1976.

\section{ROMENCLATURE}

$B_{\max }$ - Maximum magnetic Induction on conductor, $T$

$\dot{B} \quad$ - Rate of change of the magnetic Induction, $T /$ sec

$\phi_{0} \quad$ - Flux inside conductor region, ib

$\phi_{\text {ext }}$ - Flux outside conductor region, Wb

Q - Loss per cycle, J/cycle

$K_{0}$ - Attenuation or amplification factor

$\Delta V$ - Compensated loss voltage ( $\left.=d \phi_{0} / d t\right), v$

I - Transport current in magnet, $A$

M - Magnetization, A/m

$\mathrm{M}_{\mathrm{T}}$ - Resanent magnetization, $\mathrm{A} / \mathrm{m}$

H - Magnetic fleld strength, $A / m$

$\Delta v_{1}$ - Volume of the 1-th element of the magnet winding, $\mathrm{m}^{3}$

f - Fraction of superconductor in magnet winding

$b_{1}$ - Magnetic field induction at the 1 -th voluse element produced by unit transport current, T/A

$h_{1}-b_{1} / \omega_{0}$

$\tau_{0}$ - Effective time constant for unsymetrical ramp current, sec

$\tau_{d}$ - Magnet discharge time constant, sec

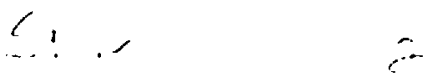




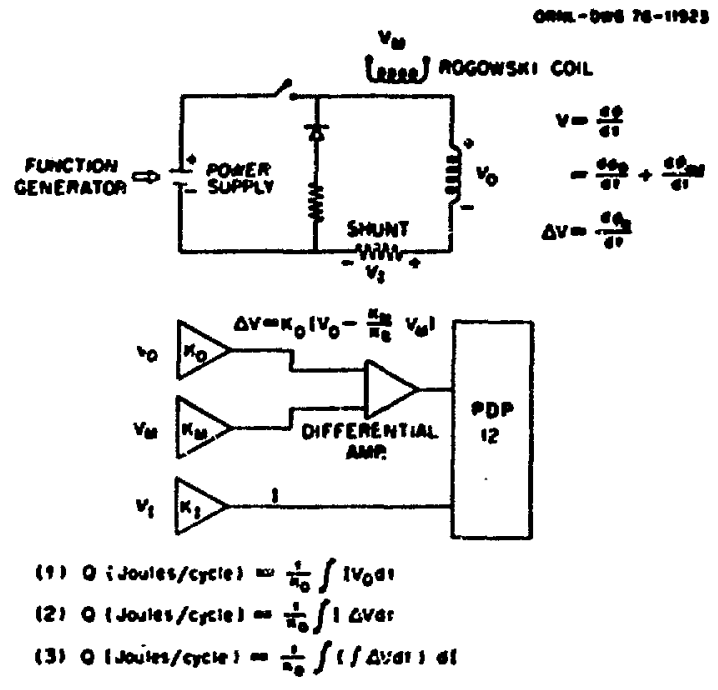

Fig. 1. Schematic dlagram of loss wasurcment systes.
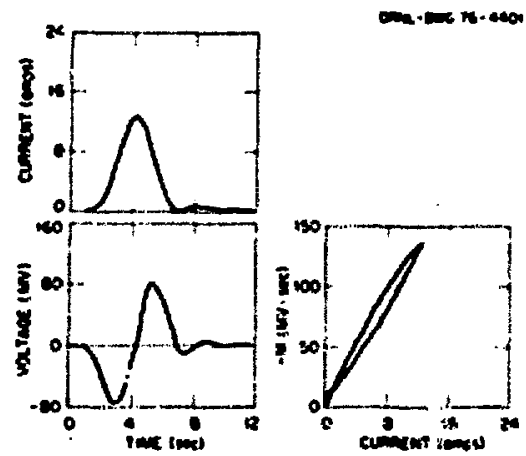

18. 2. Typlcal teat current, and compensated voltage waveforn and $0-1$ curve.

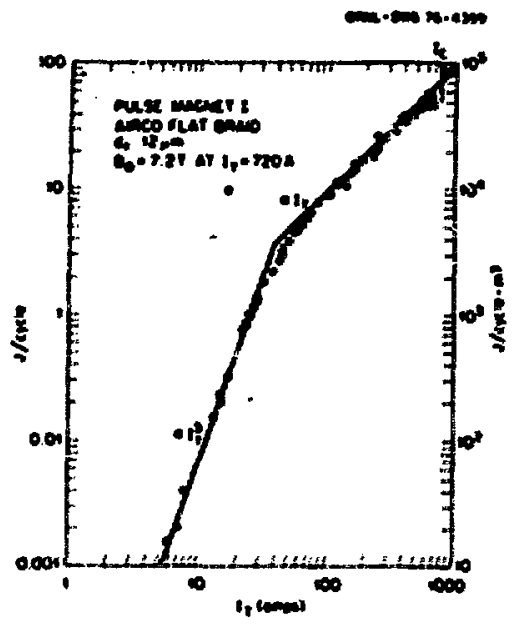

15. 3. Hyetcresis Loses vs traneport current for ragnet $t$.

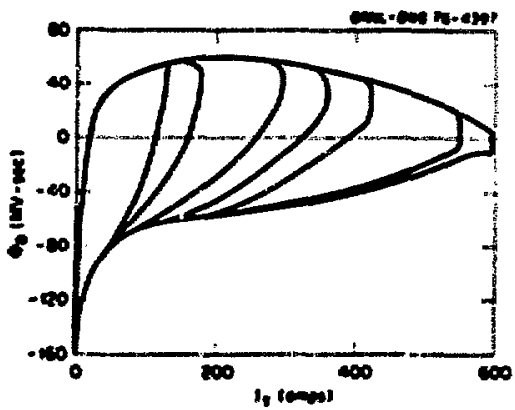

75. 4. Sertes of 0-1 curve for monotonteslly decreasios abplitude se pulsing eurrent - Mignet $I$.

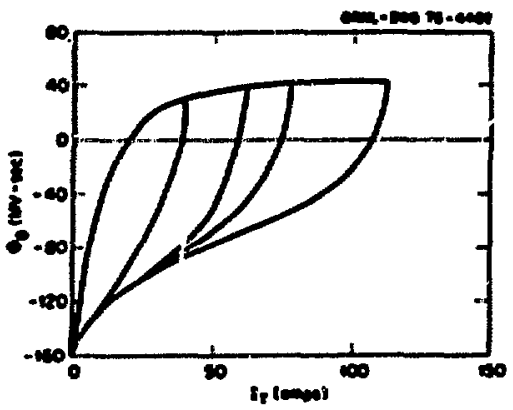

Fis. S. Sertes of -1 curwe for monotonically decreasing anplitude of pulsine current - Mapper $I$. 


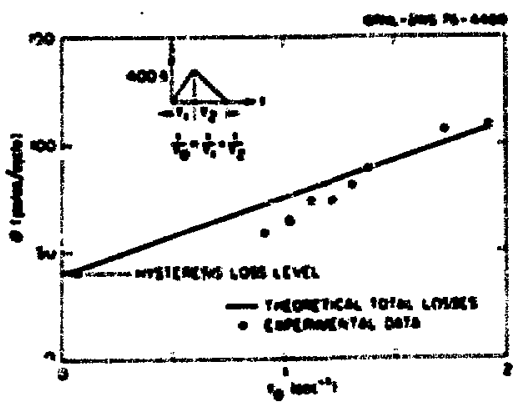

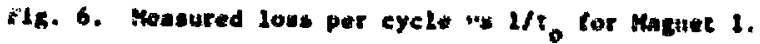

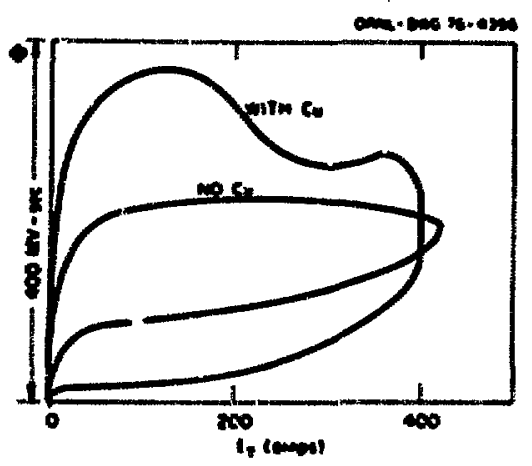

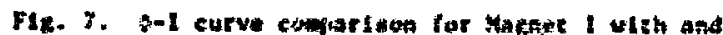
uthoul Cu Instide the hore.

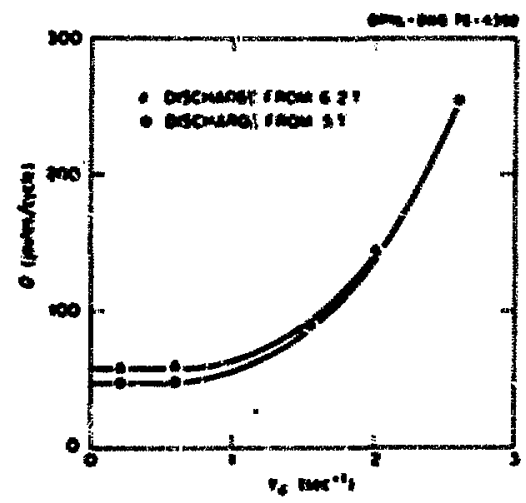

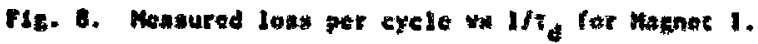

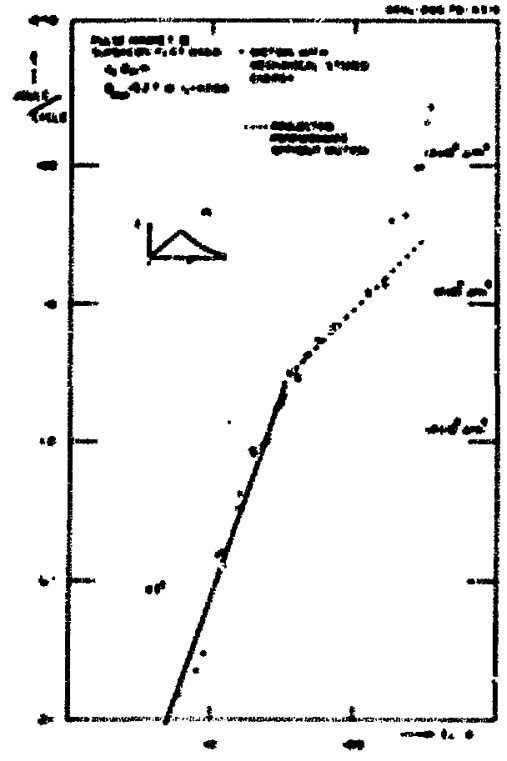

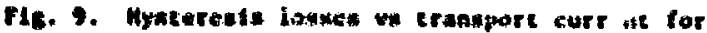
Hatate 11.

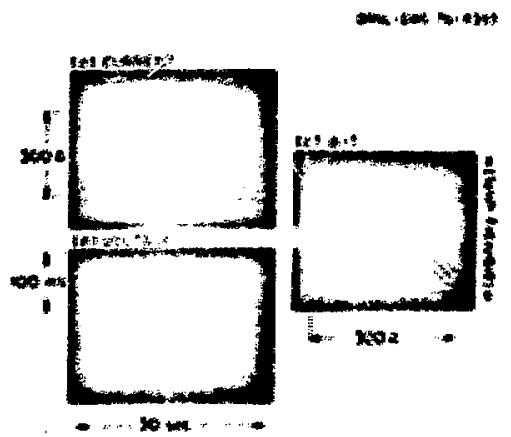

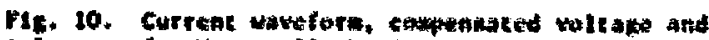

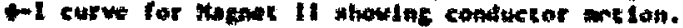

